\title{
Estimation of three-dimensional structure of forest and development of roots of trees using LiDAR data
}

\author{
Mamoru KOARAI $^{\mathrm{a},}{ }^{*}$, Akane NARIKIYO $^{\mathrm{a}}$, Wataru MURAKAMI ${ }^{\mathrm{b}}$ \\ ${ }^{a}$ Ibaraki University, mamoru.koarai.sci@vc.ibaraki.ac.jp \\ ${ }^{b}$ Department of Disaster Prevention, Meteorology and Hydrology, Forestry and Forest Products Research Institute, Ibaraki, Japan \\ * Corresponding author
}

Keywords: three-dimensional structure of forest, development of root, slope collapse, LiDAR

\begin{abstract}
:
There is deterrent effect to the slope collapse for development of the root of the tree. However, it's difficult to know the development situation of the roots of the forest. On the other hand, they're becoming able to estimate the forest threedimensional structure such as the tree height, the tree number and diameter breast height, etc. by LiDAR data. Because tree height and diameter are related to development of roots of trees, the authors try to estimate the root system development situation of the forest by LiDAR data to presume indirectly the stability of slope. The authors surveyed the diameters and root system development of about one hundred trees in the cut forest of cedar woods in the weathered granite Abukuma Mountains, Fukushima Prefecture. The three-dimensional structure of the cut forest was presumed from LiDAR data before felling. As the results of consideration, this report show that the three-dimensional structure of the forest is presumed from LiDAR data, and the development situation of the roots of the forest was estimated for slope stability analysis.
\end{abstract}

